Revista de

Contabilidade e

Organizações

www.rco.usp.br
DOI: http://dx.doi.org/10.11606/rco.v11i31.134462
Journal of

Accounting and

Organizations

\title{
Características da estrutura organizacional dos clubes de futebol brasileiros: o que dizem os estatutos?
}

Characteristics of the organizational structure of the brazilian football clubs: what do the statutes say?

Monique Cristiane de Oliveira ${ }^{a}$; José Alonso Borba ${ }^{\text {a }}$, Denize Demarche Minatti Ferreira ${ }^{\text {a }}$, Rogério João Lunkes ${ }^{\text {a }}$

${ }^{a}$ Universidade Federal de Santa Catarina

Palavras-chave

Clubes de futebol.

Estatuto Social.

Estrutura Organizacional.
Keywords

Football/soccer teams.

Social Statute.

Organizational Structure.
Informações do Artigo

Recebido: 15 de julho de 2017

Aceito: 15 de janeiro de 2018

\begin{abstract}
Resumo
Este estudo objetiva identificar as características da estrutura organizacional dos clubes profissionais de futebol no Brasil. A análise de conteúdo nos estatutos sociais de 17 clubes da "Série A" do Campeonato Brasileiro de 2016 identificou os órgãos e as funções atribuídas a cada um nos estatutos. Os órgãos presentes em todos os clubes são Assembleia Geral, Conselho Fiscal e Conselho Deliberativo. O desenho dos estatutos leva à interpretação de que o Conselho Deliberativo, pelas suas atribuições, tem influência sobre os demais órgãos, apesar de a Assembleia Geral ser mencionada como 'soberana'. Os estatutos são omissos a respeito da responsabilidade financeira que prejudique o patrimônio, e também, sobre a definição da remuneração da Diretoria. Os estatutos, também, são omissos quanto ao estabelecimento da responsabilidade financeira, seja presente ou futura. Como implicações, as omissões ou lacunas estatutárias potencializam conflitos e podem afetar a interação de gestores, dirigentes e torcedores, prejudicando a gestão e a governança dos clubes brasileiros.
\end{abstract}

\begin{abstract}
This study aims to identify the organizational structure of Brazilians professional football/soccer teams. The content analysis in the bylaws of 17 clubs in the Brazilian Premier League for 2016 season identified the collegiate decision units, and its competences assigned by each team' bylaws. The regular mentioned decision units are the General Assembly, the Fiscal Council and the Deliberative Council. The statute's design allows to support that the Deliberative Council has competences to influence the remaining councils, but the General Assembly is considered the sovereign in all clubs. The statutes are absent about financial responsibility and about the assignment of Executive Officers' salaries. The statutes are similarly absent about the establishment of present or future financial liability. The implications of such scenario are the increase on potential conflicts, furthermore these statutory omissions may affect how managers, leaders and supporters interact and behave, damaging the management and governance of Brazilian football/soccer teams.
\end{abstract}

\section{Implicações práticas}

Os estatutos dos principais clubes de futebol brasileiros são omissos quanto à responsabilidade financeira e à remuneração de seus dirigentes. Estas e outras lacunas identificadas no estudo apontam a necessidade de melhoria na estrutura de governança dessas organizações. Tais lacunas geram insegurança administrativa e dúvidas quanto aos resultados financeiros e esportivos.

Copyright (C) 2017 FEA-RP/USP. Todos os direitos reservados

\section{INTRODUÇÃO}

Clubes de futebol, enquanto organizações sociais, iniciaram o processo de profissionalização na Europa na década de 1990. A finalidade era melhorar o desempenho esportivo, transformando a organização em clubeempresa com lógica de mercado, o que profissionalizaria o esporte e promoveria o equilíbrio entre desempenho esportivo e financeiro.

Autor Correspondente: Tel. (48) 3721-9000

E-mail: monique_bona@hotmail.com (M. C. Oliveira); j.alonso@ufsc.br (J. A. Borba); denize.minatti@ufsc.br (D. D. M. Ferreira); rogeriolunkes@hotmail.com (R. J. Lunkes)

Universidade Federal de Santa Catarina. Campus Reitor João David Ferreira Lima, s/n - Trindade, Florianópolis - SC, 88040-900, Brasil 
Enquanto o esporte está em processo de profissionalização em diferentes países, no Brasil tem andado a passos curtos desde a chegada da mídia esportiva por meio dos canais pagos direcionados ao esporte (Mattar, 2014). Medidas públicas foram instituídas para auxiliar nesta mudança, como a Lei Pelé, a Lei Zico e, recentemente, o Programa de Modernização da Gestão e de Responsabilidade Fiscal do Futebol Brasileiro (PROFUT).

Juntas, estas legislações estabeleceram exigências, como a publicação de demonstrativos contábeis auditados nos padrões exigidos pelo Conselho Federal de Contabilidade (CFC), a divulgação de estatutos sociais e a prestação de contas anuais aos órgãos responsáveis pela fiscalização financeira e esportiva. Além disso, o PROFUT faz exigências em questões de gestão e estrutura organizacional dos clubes, como a autonomia e independência do Conselho Fiscal e o tempo de mandato dos presidentes, em troca de parcelamento de débitos com o Governo Federal e o perdão das multas e encargos.

Embora os clubes de futebol brasileiros sejam considerados associações sem fins lucrativos, com o desenvolvimento do esporte como negócio, tais organizações se voltaram ao resultado financeiro. Atualmente, quanto mais campeonatos conquistados, mais jogadores são revelados e mais caixa é gerado para os clubes. Contudo, para conquistar títulos é preciso investir em estrutura e atletas (Bács, 2014). Desta forma, há um looping entre o desempenho financeiro e esportivo, onde os clubes brasileiros não conseguem atingir o equilíbrio devido aos seus altos prejuízos associados a grandes valores de dívidas.

Isso ocorre porque os clubes não possuem estratégias de negócios bem definidas, capazes de gerar oportunidade e atrair parceiros e investidores (Fatta et al., 2016). A estrutura organizacional fica comprometida, pois seria uma consequência da estratégia (Gurianova \& Mechtcheriakova, 2015) capaz de captar as mudanças do ambiente com maior facilidade.

As receitas provocaram um salto no desenvolvimento do futebol como negócio (Mattar, 2014), mas a gestão ineficiente nos clubes e federações é evidente e precisa ser estudada. A utilização de mecanismos empresariais nos clubes afeta a gestão, podendo alterar a estrutura organizacional (Rodrigues \& Silva, 2009). A falta de estrutura bem definida é uma das causas de o futebol brasileiro não ter alcançado o patamar de profissionalização do esporte como ocorrido em outros países (Mattar, 2014).

Entender como estão estruturados os clubes é o primeiro passo para compreender as dificuldades encontradas no processo de profissionalização. $\mathrm{O}$ estudo dessa estrutura visa contribuir para o aprimoramento da gestão do futebol no Brasil, bem como abrir espaço para a análise do cenário esportivo no país e o entendimento da estrutura organizacional dos clubes, considerada um dos pilares da ineficiência da gestão (Mattar, 2014). Além disso, visa proporcionar uma base informativa para pesquisas futuras, que, ainda, são escassas tanto nacionais como internacionais (Fatta et al., 2016), mesmo diante da evidente relevância que possuem para este tipo de negócio.

Para atender esta demanda, o presente estudo tem como objetivo analisar a estrutura organizacional dos clubes de futebol profissionais no Brasil. Esse entendimento serviria de base para compreender como tal estrutura pode ser uma limitação na profissionalização dos clubes de futebol no país. A análise foi feita em 20 clubes participantes da "Série A" do Campeonato Brasileiro de 2016. Cabe ressaltar que, com as diferentes medidas do Governo para contribuir com a transformação positiva do futebol, as discussões acerca do tema devem ganhar ênfase na academia e no mercado, de forma que estudos sobre as características organizacionais serão mais demandados.

Tal profissionalização é importante à medida que recursos públicos estão sendo utilizados para auxiliar o equilíbrio financeiro dos clubes, embora não se saiba os motivos de fato, que impeçam os clubes operarem de forma sustentável. A expectativa é de que o aprimoramento da gestão torne o mercado de futebol, como um todo, mais forte e competitivo. Além disso, tal aprimoramento traria melhor desempenho esportivo, público para os estádios, e consequentemente, mais renda e melhor imagem. Por fim, os clubes brasileiros poderiam manter por mais tempo os seus melhores jogadores e ou contrapor as propostas de clubes estrangeiros, principalmente europeus e asiáticos.

\section{LITERATURA ANTERIOR E CONTEXTO BRASILEIRO}

O futebol brasileiro modificou suas características estruturais, transformando-se em um negócio a partir dos anos 1990 (Mattar, 2014). Neste período, os clubes realizaram parcerias para atuarem na sua gestão (Leoncini \& Silva, 2005), exigindo readequações estruturais para a lógica empresarial, capaz de profissionalizar a gestão e adequar a estrutura dos clubes (Rodrigues \& Silva, 2009). As parcerias visavam, ainda, auxiliar a melhora dos resultados econômicos e/ou esportivos (Fatta et al., 2016). 
As mudanças estruturais também ocorreram em função das pressões externas, sofridas devido ao desenvolvimento do negócio futebol (Relvas et al., 2010). Esta estrutura é definida e controlada pelos seus estatutos, que "[...] representam os códigos que resumem os princípios fundamentais, as normas e os textos de aplicação que deverão ser seguidos pela diretoria executiva [...]”, bem como pelos conselhos deliberativo e consultivo, que são órgãos de assessoramento (Carravetta, 2006, p.45).

O grau de profissionalização do clube define o tamanho da diretoria e dos departamentos (Costa \& Silva, 2006), que será maior à medida que o clube se torna mais empresariado. Equipes de futebol profissionais modernas e bem-sucedidas precisam de uma gestão de alto nível para conciliar e suprir as necessidades de todas as partes interessadas, que aumentam significativamente à medida que o clube se profissionaliza (Bács, 2014).

Ainda que, a estrutura organizacional tenha importância no processo de gestão e possa ser constituída como base para o sucesso dos clubes de futebol, é também um dos fatores que barra o crescimento e profissionalização do futebol brasileiro, limitando a atuação de uma administração eficiente e profissional no país (Mattar, 2014).

Embora, exista ênfase sobre a necessidade de uma estrutura organizacional bem definida e aliada com as estratégias dos clubes, são poucos os estudos sobre o tema por autores brasileiros. Menciona-se a seguir três estudos acerca do tema.

Recentemente, Fatta et al. (2016) revisaram as publicações sobre a gestão e a estrutura organizacional de clubes de futebol brasileiros. Os autores revisaram as bases SPORTDiscus e Web of Science e identificaram oito trabalhos, que convergem nas evidências de que os clubes brasileiros possuem uma gestão amadora, inviabilizando atrair parceiros de negócios por não possuir uma estrutura organizacional e modelo de gestão bem definidos.

Especificamente, Rodrigues e Silva (2009) estudaram os impactos da adoção da lógica empresarial na estrutura organizacional do Figueirense Futebol Clube e do Sport Club Internacional. Os resultados indicavam que as equipes estavam em estágios diferentes de adoção de suas estruturas profissionais. Enquanto o Figueirense ampliava a sua estrutura, o Internacional a enxugava, pois estava voltado para a obtenção de resultado financeiro.

Analisando clubes europeus, Relvas et al. (2010) verificaram a relação entre as diferentes estruturas organizacionais, práticas de trabalho e filosofia no desenvolvimento de programas de categorias de base. Comparando 26 clubes profissionais de cinco países da Europa, os autores verificaram uma homogeneização da estrutura organizacional nesses clubes, principalmente a existência de um departamento exclusivo de categorias de base. Porém, o que falta é a comunicação entre os departamentos como forma de melhorar o desenvolvimento destes programas e, portanto, revelar jogadores próprios.

\section{PROCEDIMENTOS METODOLÓGICOS}

A amostra deste estudo foi composta pelos 20 clubes participantes da Série A do Campeonato Brasileiro, sendo o objeto de estudo os estatutos sociais destas entidades, especificamente as seções que tratam da estrutura organizacional (órgãos/poderes sociais). Dos 20 clubes, foram analisados 17 estatutos, pois os documentos dos clubes Chapecoense, Cruzeiro e Sport não estavam disponíveis.

Os documentos analisados neste estudo referem-se aos estatutos disponíveis nos websites dos clubes em outubro/16. Após esta data, 7 clubes já atualizaram seus estatutos (Botafogo, Grêmio, América, Corinthians, São Paulo, Flamengo e Vitória).

Inicialmente, os estatutos foram lidos e as seções, que tratavam da configuração estrutural dos clubes, identificadas. Em seguida, uma nova leitura foi realizada, apenas nas seções de estrutura organizacional, a fim de identificar todos os órgãos que formavam o desenho estrutural das entidades. Para cada órgão identificado foram levantadas informações sobre a composição, finalidades e competências.

Com base na denominação foram identificados 22 diferentes tipos de órgãos sociais. Tais estruturas foram reunidas em uma tipologia padrão, dada a diversidade de nomenclaturas utilizada nos diversos clubes para órgãos com funções similares. Para tanto, foram comparadas a composição, finalidades e competências dos órgãos entre os clubes para classificá-los.

No Santos não havia Diretoria, mas um Comitê de Gestão e Administração Executiva, agregados e considerados como tal. No Grêmio havia Gerência Executiva, Presidência e Vice-Presidências, as quais, pelas funções exercidas, assemelhavam-se às Diretorias estabelecidas por outros clubes, sendo estes classificados apenas como um. Já no Santa Cruz, mencionava-se o Executivo, sendo considerado como órgão diretor. No Atlético MG, as Comissões foram agregadas à Diretoria. 
Quanto ao Conselho Fiscal, foram agregados a ele uma Comissão Fiscal e um Conselho de Orientação e Fiscalização. O Palmeiras não identificava em sua estrutura um órgão denominado Conselho Fiscal, mas pelas competências, se assemelhava ao referido órgão em outros clubes. O Corinthians possui o Conselho de Orientação (CORI), em que algumas competências se assemelham ao fiscal, porém, já constava um poder com este nome, sendo agrupado como Conselho Administrativo.

Portanto, foram identificados os órgãos mais citados nos estatutos e definiu-se uma configuração estrutural básica para os clubes. Foi realizado um corte nos órgãos analisados, sendo considerados apenas aqueles presentes em, no mínimo, 40\% dos estatutos sociais. O Quadro 1 apresenta a identificação final dos órgãos de acordo com os clubes.

\begin{tabular}{|c|c|c|c|c|c|c|c|c|c|}
\hline \multirow[b]{2}{*}{ Clube } & \multirow{2}{*}{$\begin{array}{l}\text { Forma } \\
\text { Jurídica }\end{array}$} & \multirow{2}{*}{$\begin{array}{c}\text { Data do } \\
\text { Estatuto } \\
\text { Vigente }\end{array}$} & \multirow{2}{*}{$\begin{array}{l}\text { Data do } \\
\text { Estatuto } \\
\text { Analisado }\end{array}$} & \multicolumn{6}{|c|}{ Órgãos Sociais } \\
\hline & & & & AG & $\mathbf{C F}$ & CD & D & $\mathbf{C C}$ & CA \\
\hline América Futebol Clube & ASFL & $31 / 08 / 2017$ & 2015 & M & M & M & M & M & M \\
\hline Grêmio Foot-Ball Porto Alegrense & ASFL & $24 / 06 / 2017$ & 2015 & M & M & M & M & M & M \\
\hline Associação Atlética Ponte Preta & ASFL & $01 / 12 / 2015$ & 2014 & M & M & M & M & M & - \\
\hline Botafogo de Futebol e Regatas & ASFL & $08 / 08 / 2017$ & $2008^{*}$ & M & M & M & M & M & - \\
\hline Fluminense Football Club & - & $27 / 08 / 2016$ & 2001 & M & M & M & M & M & - \\
\hline Santos Futebol Clube & ASFL & - & - & M & M & M & M & M & - \\
\hline São Paulo Futebol Clube & ASFL & $01 / 01 / 2017$ & 2011 & M & M & M & M & M & - \\
\hline Clube Atlético Mineiro & ASFL & $24 / 08 / 2015$ & 2008 & M & M & M & M & - & - \\
\hline Clube Atlético Paranaense & ASFL & $08 / 12 / 2014$ & 2014 & M & M & M & M & - & M \\
\hline Clube de Regatas do Flamengo & ASFL & $05 / 06 / 2017$ & 2015 & M & M & M & M & - & M \\
\hline Esporte Clube Vitória & ASFL & $02 / 04 / 2017$ & 2008 & M & M & M & M & - & - \\
\hline Santa Cruz Futebol Clube & NI & $15 / 08 / 2013$ & 2007 & M & M & M & M & - & - \\
\hline Sport Club Corinthians Paulista & ASFL & $01 / 02 / 2017$ & 2015 & M & M & M & M & - & M \\
\hline Sport Club Internacional & ASFL & $23 / 05 / 2016$ & 2014 & M & M & M & M & - & - \\
\hline Coritiba Foot Ball Club & ASFL & $20 / 02 / 2011$ & 2011 & M & M & M & - & M & M \\
\hline Figueirense Futebol Clube & ASFL & $02 / 09 / 2013$ & 2013 & M & M & M & - & - & M \\
\hline Sociedade Esportiva Palmeiras & ASFL & $08 / 12 / 2006$ & $2006^{* *}$ & M & M & M & - & - & - \\
\hline
\end{tabular}

Quadro 1. Informações gerais dos clubes brasileiros participantes da Série A de 2016.

Fonte: Elaborado pelos autores.

Legenda: ASFL - Associação Sem Fins Lucrativos; AG - Assembleia Geral; CF - Conselho Fiscal; CD - Conselho Deliberativo; D - Diretoria; CC - Conselho Consultivo; CA - Conselho Administrativo; M - Menciona; NI - Não Menciona/ ou não informado (no Estatuto Social).

* Encontrado no site, mas não em documento.

** O Clube apresenta, nas disposições iniciais, que o estatuto foi aprovado em reunião em 2013, porém, nas disposições finais, aponta que entrou em vigor em 2006, sendo apontada neste trabalho esta data como a última atualização do estatuto.

Selecionados os órgãos a serem estudados, procedeu-se à tabulação e padronização dos textos a serem analisados. Foi feita uma análise de conteúdo utilizando a técnica de Análise de Semelhança, identificando a ocorrência das palavras e a ligação entre as mesmas, para reconhecer uma estrutura de conteúdo organizada. $\mathrm{O}$ software utilizado foi o IRAMUTEQ.

As palavras, que mais aparecem nos textos analisados, foram verificadas e em seguida agrupadas em nuvens de palavras, a partir das relações encontradas. Em seguida, dessa associação emergiram os mecanismos de governança. $\mathrm{Na}$ análise de conteúdo, 3 categorias foram inicialmente alvo de extração do conteúdo dos documentos: a composição, as finalidades e as competências de cada órgão (Tabela 1).

Para cada um dos 6 órgãos identificados foram analisadas separadamente cada uma das 3 categorias (composição, finalidades e competências), resultando em 18 análises . Os resultados preliminares identificaram as principais características destes órgãos, pela relação entre as palavras mais citadas em cada texto. A análise resultou em 98 atributos distribuídos entre os órgãos. Em seguida, estas informações foram reunidas em uma lista e, com base no julgamento dos autores, foram sintetizadas, reescritas e reorganizadas para evitar duplicidade de informações, totalizando 43 mecanismos de governança (Tabela 2) a serem avaliados. 
Tabela 1. Estatutos por órgão e categoria analisada

\begin{tabular}{lccc}
\hline \multirow{2}{*}{ Órgão Social } & \multicolumn{3}{c}{ Categorias } \\
\cline { 2 - 4 } & Composição & Finalidades & Competências \\
\hline Assembleia Geral & 16 & 15 & 15 \\
Conselho Fiscal & 17 & 6 & 17 \\
Conselho Deliberativo & 17 & 15 & 17 \\
Diretoria & 13 & 2 & 10 \\
Conselho Consultivo & 7 & 3 & 5 \\
Conselho Administrativo & 7 & 2 & 7 \\
\hline Fonte: Elaborado pelos autores. & & &
\end{tabular}

Os mecanismos de governança foram classificados conforme: (i) a autonomia operacional, (ii) o controle cruzado de outro órgão da estrutura, (iii) as questões que demandam votação do próprio colegiado, (iv) o tempo de mandato, (v) a quantidade de membros e, (vi) o tempo de associação. Tal classificação reconhece determinadas ações como decisões exclusivas dos órgãos, que demandam votação ou não e que órgãos podem tomar decisões acerca de outros.

As informações de tempo de mandato, quantidade de membros e tempo de associação foram classificadas pelo volume de informações sobre a composição dos órgãos. A partir desta definição, voltou-se aos estatutos, individualmente, para verificar em que conselhos os mecanismos se encontravam.

Salienta-se que a análise proposta neste estudo traz apenas evidências apresentadas nos documentos disponibilizados pelos clubes, e não confronta os mesmos com as atividades exercidas por cada órgão na prática. O objetivo não é inferir sobre a real operação e funcionamento dessas estruturas, nem se tais estruturas foram montadas apenas para fins de atendimento da legislação, mas identificar possíveis brechas nas formas de gestão dos clubes. Para tanto, as principais incongruências de governança encontradas foram discutidas a partir do entendimento dos autores acerca das informações levantadas.

\section{ANÁLISE E DISCUSSÃO DOS RESULTADOS}

A Tabela 2 apresenta as informações sobre os mecanismos de governança identificados a partir da análise de conteúdo nos estatutos sociais.

A eleição do presidente e vice-presidente do Conselho Deliberativo e a quantidade de membros, que compõe o Conselho Fiscal, foram os únicos mecanismos presentes em todos os estatutos. O orçamento dos clubes é o assunto mais apresentado e não passam pela aprovação da Assembleia Geral ou pelo Conselho Consultivo, sendo de competência do CF e do CD, órgãos mais incisivos na fiscalização financeira e administrativa dos clubes.

Em geral, o órgão com maior desempenho de funções é o Conselho Deliberativo, corroborando a existência dada a este por Carravetta (2006), que também é considerado um órgão altamente político. Por ser um órgão deliberativo, não causa estranhamento a quantidade de assuntos que cabem à votação no órgão.

A concentração das decisões denotadas como autonomia operacional pode indicar que a influência exercida dentro do clube tende a ser individualizada, dificultando a mudança para uma estrutura profissionalizada. As informações de controle cruzado, que poderiam inibir o exercício da influência isolada no clube devido ao envolvimento de indivíduos de diferentes poderes, são em menor número e indicam a necessidade de reavaliação das competências na tentativa de legitimar um modelo de estrutura organizacional mais profissional. 
Tabela 2. Apresentação das funções por classificação e órgão social

\begin{tabular}{|c|c|c|c|c|c|c|}
\hline $\begin{array}{c}\text { Órgão } \\
\text { Mecanismo }\end{array}$ & $\begin{array}{c}\text { Assembleia } \\
\text { Geral }\end{array}$ & $\begin{array}{c}\text { Conselho } \\
\text { Fiscal }\end{array}$ & $\begin{array}{c}\text { Conselho } \\
\text { Deliberativo }\end{array}$ & Diretoria & $\begin{array}{c}\text { Conselho } \\
\text { Consultivo } \\
\end{array}$ & $\begin{array}{l}\text { Conselho } \\
\text { Administ }\end{array}$ \\
\hline \multicolumn{7}{|l|}{ Autonomia Operacional } \\
\hline Acompanhar e/ou fiscalizar da administração financeira e/ou os atos de gestão & & 7 & 4 & 2 & & \\
\hline Aconselhar e/ou opinar sobre a conservação das tradições éticas, filosóficas e históricas & & & & & 2 & \\
\hline Administrar, zelar pelo patrimônio e imagem e/ou defender os interesses do clube & & 2 & 2 & 14 & 1 & 3 \\
\hline Analisar, avaliar, e/ou apresentar as Demonstrações Financeiras e os balancetes & 1 & 17 & 8 & 6 & & 2 \\
\hline Autorizar a contratação e/ou demissão de funcionários & & & & 7 & & 5 \\
\hline Dar parecer a respeito da prestação de contas do clube & & 4 & 5 & 11 & & \\
\hline Dar provimento de cargos & 7 & & 1 & 1 & & \\
\hline Elaborar o próprio regimento interno & & 4 & 11 & 9 & & 5 \\
\hline Elaborar o regimento interno do clube & & & 4 & & & \\
\hline Escolher e/ou contratar os serviços de auditoria independente & & 4 & 4 & & & 3 \\
\hline Fixar a remuneração da diretoria & & & & 3 & & 3 \\
\hline Fixar as quantias a serem pagas pelos associados, sua admissão ou destituição & & & 7 & 5 & & 5 \\
\hline Instituir e/ou destituir as diretorias/comissões de acordo com as necessidades & & & 7 & 9 & & 4 \\
\hline Orientar, fiscalizar e/ou aprovar das atividades do clube e a gestão dos negócios & 1 & 11 & 8 & 1 & 2 & 4 \\
\hline Representar o clube em todos os âmbitos & & & 1 & 11 & & 4 \\
\hline \multicolumn{7}{|l|}{ Controle cruzado de outro órgão da estrutura } \\
\hline Comunicar ao CD qualquer circunstância lesiva ou que possa vir a ser prejudicial & & 15 & & & & 2 \\
\hline Cumprir, fazer cumprir e/ou fiscalizar as deliberações do CD, CF, AG, Estatuto Social & & 6 & 3 & 12 & & 5 \\
\hline Elaborar os orçamentos geral e por diretoria e submeter à apreciação do CD & & 1 & & 9 & & 1 \\
\hline Fazer recomendações à Diretoria sobre sua organização e aplicação de verbas & & 3 & & & & \\
\hline Nomear ou destituir membros da Diretoria & & & 1 & 6 & & 4 \\
\hline Prestar contas acompanhadas do parecer da auditoria independente e enviar ao CF e CD & & & & 10 & & 3 \\
\hline Respeitar e fiscalizar o cumprimento das deliberações do CD & & 1 & 2 & 3 & & 1 \\
\hline \multicolumn{7}{|l|}{ Questões que demandam votação do próprio colegiado } \\
\hline Apresentar parecer sobre o movimento econômico, financeiro e/ou administrativo & & 5 & 1 & & & \\
\hline Apresentar parecer sobre a fiscalização da execução do orçamento & & 7 & 1 & & & \\
\hline Analisar, discutir, votar e fiscalizar o cumprimento do planejamento estratégico do clube & & & 1 & 5 & 1 & 2 \\
\hline Decidir sobre as transações de bens patrimoniais & 4 & 3 & 13 & & 1 & 1 \\
\hline Deliberar e/ou manifestar-se sobre responsabilidade financeira grave & & & 1 & & 1 & \\
\hline Deliberar e/ou manifestar-se a respeito das alterações no Estatuto Social & 11 & 1 & 13 & 1 & 1 & 1 \\
\hline Deliberar e/ou manifestar-se a respeito de quaisquer situações relevantes & & 2 & 13 & & 5 & \\
\hline Deliberar e/ou dar parecer sobre a orçamentos e/ou a necessidade de créditos adicionais & & 13 & 13 & 2 & & 5 \\
\hline Analisar e aprovar as Demonstrações Contábeis e outros documentos da contabilidade & & 8 & 13 & & 1 & 1 \\
\hline Deliberar, julgar e/ou processar membros de órgãos e/ou demais associados & 5 & & 15 & 1 & & 1 \\
\hline
\end{tabular}

Fonte: Elaborado pelos autores.

Legenda: Legenda: AG - Assembleia Geral; CF - Conselho Fiscal; CD - Conselho Deliberativo; D - Diretoria; CC - Conselho Consultivo; CA - Conselho Administrativo. 
Tabela 2. Apresentação das funções por classificação e órgão social (continuação)

\begin{tabular}{|c|c|c|c|c|c|c|}
\hline $\begin{array}{c}\text { Órgão } \\
\text { Mecanismo }\end{array}$ & $\begin{array}{c}\text { Assembleia } \\
\text { Geral }\end{array}$ & $\begin{array}{c}\text { Conselho } \\
\text { Fiscal } \\
\end{array}$ & $\begin{array}{c}\text { Conselho } \\
\text { Deliberativo }\end{array}$ & Diretoria & $\begin{array}{c}\text { Conselho } \\
\text { Consultivo }\end{array}$ & $\begin{array}{r}\text { Conselho } \\
\text { Administ. }\end{array}$ \\
\hline \multicolumn{7}{|l|}{ Questões que demandam votação do próprio colegiado } \\
\hline Eleger, empossar e/ou destituir os membros da Diretoria & 2 & & 5 & & & \\
\hline Eleger, empossar e/ou destituir os membros do CA & 3 & & 5 & & & \\
\hline Eleger, empossar e/ou destituir os membros do CD & 16 & & & & & \\
\hline Eleger, empossar e/ou destituir os membros do CF & 8 & & 16 & & & \\
\hline Eleger o Presidente e o Vice-Presidente & & & 3 & & & \\
\hline Eleger o próprio Presidente e Vice-Presidente & & 10 & 17 & & 2 & 1 \\
\hline Examinar e dar parecer sobre balancetes, contas, relatórios e documentos fiscais & & 16 & 3 & & & 2 \\
\hline Extinção, fusão, incorporação, cisão do clube e demais alterações jurídicas & 16 & 1 & 12 & & 3 & \\
\hline \multicolumn{7}{|l|}{ Tempo de mandato } \\
\hline Não apresentaram informação & 17 & 2 & 3 & 8 & 13 & 12 \\
\hline \multicolumn{7}{|l|}{ Menos de 2 anos } \\
\hline Entre 2 e 5 anos & & 15 & 11 & 9 & 3 & 5 \\
\hline Superior a 5 anos & & & 3 & & 1 & \\
\hline \multicolumn{7}{|l|}{ Quantidade de membros } \\
\hline Não apresentaram informação & 17 & & 1 & 7 & 16 & 11 \\
\hline Inferior a 100 & & 17 & & 10 & & 6 \\
\hline Entre 100 e 300 & & & 9 & & & \\
\hline Superior a 300 & & & 7 & & 1 & \\
\hline \multicolumn{7}{|l|}{ Tempo de associação } \\
\hline Não apresentaram informação & 2 & 17 & 10 & 13 & 17 & 15 \\
\hline Inferior a 2 anos & 4 & & 2 & & & \\
\hline Entre 2 e 5 anos & 9 & & 4 & 2 & & 1 \\
\hline Superior a 5 anos & 2 & & 1 & 2 & & 1 \\
\hline
\end{tabular}

Fonte: Elaborado pelos autores.

Legenda: Legenda: AG - Assembleia Geral; CF - Conselho Fiscal; CD - Conselho Deliberativo; D - Diretoria; CC - Conselho Consultivo; CA - Conselho Administrativo. 
Os estatutos, de modo geral, não são claros sobre as responsabilidades de contratação e/ou demissão de jogadores e comissão técnica. Poucos estatutos tratam deste ponto, e da forma como estão apresentados, tal mecanismo cobre apenas o quadro de funcionários administrativos do clube. Isso sugere uma falha de governança. Como não há responsabilização por contrações e/ou demissões equivocadas, eventuais contratações "em pacote" são incentivadas, assim como uma maior troca de técnicos, como se observa nos clubes ao longo das temporadas brasileiras. Não há direcionamento nem fiscalização das responsabilidades, de forma que, contratações erradas podem acarretar em despesas elevadas ao clube. Além disso, não há detalhamento dos responsáveis pelas transações de compra e venda de atletas e como o processo deve ser feito.

De forma geral, vê-se que o estatuto dá margem para uma gestão menos profissional por não determinar quem responde por essas decisões e, por conseguinte, possa ser responsabilizado pelas consequências das deliberações efetuadas. Assim, a governança é afetada pois as funções de cada órgão não são claras permitindo uma atuação entre as omissões apresentadas nos estatutos.

Chama-se atenção, também, a responsabilidade da Diretoria em fixar sua própria remuneração. Diferentemente dos demais órgãos, este é o único que pode ter remuneração, mesmo não explícita em todos os estatutos, contrário ao apontado por Costa e Silva (2006), a respeito da remuneração da diretoria em entidades sem fins lucrativos. A explicação dada pelos autores é que a remuneração pode ocorrer quando os clubes terceirizam sua administração. Nos demais órgãos a atuação é voluntária e não exigem a atuação integral, já a Diretoria é o órgão atuante do clube, por isso tal exigência.

Foram constatados que, 7 dos 17 clubes analisados mencionavam algum tipo de remuneração para a Diretoria. Os trechos dos artigos, que tratam do tema nos estatutos, estão apresentados no Quadro 2.

\begin{tabular}{|c|c|c|}
\hline Clube & Artigo & Descrição \\
\hline Atlético Mineiro & 64 & $\begin{array}{l}\text { "No exercicio de suas funções e competência, a Diretoria será auxiliada por um corpo } \\
\text { de Diretores Adjuntos e Administradores, por ela indicados e submetidos à aprovação } \\
\text { do Conselho Deliberativo, inclusive suas respectivas remunerações, os quais exercerão } \\
\text { funções de confiança, conforme as atribuiçoes que lhes forem delegadas [...]". }\end{array}$ \\
\hline Coritiba & 112 & $\begin{array}{l}\text { "IV - aprovar a contratação de gerentes e funcionários e definir as suas remunerações, de } \\
\text { acordo com o plano de cargos e salários". }\end{array}$ \\
\hline Figueirense & 139 & $\begin{array}{l}\text { "Parágrafo único. Serão contratados e remunerados profissionais, com qualificação } \\
\text { comprovada, pelo FIGUEIRENSE, para a ocupação de chefias executivas em cada uma } \\
\text { das áreas". }\end{array}$ \\
\hline Flamengo & 68 & $\begin{array}{l}\text { "§ } 4^{\circ} \text { - Aos dirigentes não estatutários, contratados e remunerados pelo FLAMENGO, } \\
\text { impó-se as mesmas obrigações, vedações e responsabilidade exigíveis dos presidentes e } \\
\text { vice-presidentes dos Poderes do FLAMENGO, nos termos dos } \S 1^{\circ}, 2^{\circ} \text { e } 3^{o \text { " }} \text {. }\end{array}$ \\
\hline Grêmio & 94 & $\begin{array}{l}\text { "Os cargos de gerentes serão remunerados e preenchidos mediante contratos na forma da } \\
\text { lei". }\end{array}$ \\
\hline Santos & 77 & $\begin{array}{l}\text { “A Administração Executiva do SANTOS é conduzida por profissionais remunerados, } \\
\text { com qualificação comprovada, contratados pelo SANTOS em regime de tempo integral e } \\
\text { dedicação exclusiva ao SANTOS, que serão responsáveis pela execução da administração } \\
\text { geral do SANTOS, subordinados às decisões e determinações do Comitê de Gestão, com } \\
\text { remuneração fixada por este. }\end{array}$ \\
\hline Vitória & 21 & $\begin{array}{l}\text { "§ } 3^{\circ} \text { - O Conselho Diretor poderá contratar e definir remuneração de profissionais, } \\
\text { observados os valores praticados pelo mercado, para efetivamente atuarem na gestão } \\
\text { executiva ou na prestação de serviços específicos ao VITÓRIA, podendo, para tanto, criar } \\
\text { e extinguir cargos". }\end{array}$ \\
\hline
\end{tabular}

Quadro 2. Menções à remuneração de diretores nos Estatutos Sociais - 7 casos encontrados.

Fonte: Estatutos Sociais dos Clubes.

Nos casos mencionados no Quadro 2, a remuneração é permitida àqueles que contratam gestores, corroborando Costa e Silva (2006). Assim, ao contratar, a experiência profissional, formação, regime integral e dedicação exclusiva são exigidos. Desta forma, a diretoria consegue, ainda, ter profissionais remunerados, o que pode ser um fator positivo na busca de uma gestão profissionalizada, pois, quando não remunerados, embora se dediquem ao clube, diretores e conselheiros precisam dedicar-se a outra atividade que lhes dê retornos financeiros, sendo o clube uma atividade acessória. 
Entretanto, salienta-se que a própria diretoria contrata, demite e estabelece a remuneração dos diretores, não havendo segregação de funções, falha grave na governança dos clubes, no que tange a um ambiente propício para a interferência de conflitos de interesses na gestão interna dos clubes. Naturalmente, estas suposições são feitas em função das lacunas (intencionais ou não) apresentadas na interpretação dos estatutos sociais.

Ainda, a respeito das funções da Diretoria vê-se que, em muitos casos, ela é responsável não só pela prestação de contas dos clubes, mas também deve avaliar, dar parecer e fiscalizar as contas e os orçamentos. Ou seja, ela própria fiscaliza seus atos. Nota-se, outra vez, que não há segregação de funções e determinação de responsabilidade dentro da estrutura organizacional dos clubes.

A função de fiscalizar os atos de gestão e, em consequência, a prestação de contas deveria ser de responsabilidade unicamente do Conselho Fiscal, que conforme alguns estatutos, deve ter membros com formação em Ciências Contábeis. Entretanto, a aprovação das contas recai sobre o Conselho Deliberativo, órgão decisivo no clube e que possui membros com diferentes formações (ou nenhuma), que devem julgar a procedência das contas com base no parecer do Conselho Fiscal. Assim, caso o parecer seja favorável, mesmo que a prestação de contas esteja ressalvada, a apreciação pelo Conselho Deliberativo parte deste relatório e não de uma análise em conjunto, de forma que a decisão pode ser influenciada previamente.

Portanto, a autonomia e independência do Conselho Fiscal, como exige o PROFUT, mostra-se necessária, assim como a responsabilidade e ética dos membros do Conselho Fiscal, para evitar a interferência no julgamento. Contudo, os estatutos mostram uma evidente dependência entre os órgãos na tomada de decisão acerca das finanças dos clubes. Esta situação, evidentemente, instaura um ambiente de fraco controle interno e, consequentemente, baixa governança.

Em relação às eleições do Conselho Deliberativo, o que os estatutos geralmente pontuam é que os membros são eleitos pelos seus sócios, os quais compõem a Assembleia Geral nos termos dispostos nos estatutos. Entretanto, não há informações sobre a possibilidade de os membros da Diretoria fazerem parte do quadro associativo e, portanto, votarem nas eleições do clube através da Assembleia Geral. Considerando que o próprio Conselho Deliberativo tem, em alguns clubes, a responsabilidade de eleger, empossar e/ou destituir os membros da Diretoria, é possível que, diante da omissão dos estatutos sobre este ponto, membros da Diretoria escolham os participantes do Conselho Deliberativo que possam lhes empossar como diretores ou destituir aqueles que não lhe são bem vistos.

Nota-se que os estatutos são omissos quanto às discussões a respeito da responsabilidade financeira que prejudique o patrimônio do clube. Neste ponto, o impasse é que todos os órgãos poderiam deliberar a respeito, mas, ao mesmo tempo, nenhum poderia ser responsabilizado, o que pode fornecer um ambiente propício para o desenvolvimento de práticas financeiras irresponsáveis.

O acúmulo de funções entre os poderes pode impactar o fluxo de informação e gestão interna, por meio de interferência direta na maneira como cada órgão deve e exerce suas funções. Se a gestão dos clubes for operada na prática segundo mostram os estatutos, com funções sobrepostas, desviadas ou duplicadas, o resultado será maior insegurança administrativa, com impacto nos resultados esportivos. Parece que, a partir do estatuto, a subdivisão da estrutura organizacional não evita a duplicação de funções, contrariando o que foi apontado por Nagovitsin (1983).

\section{CONSIDERAÇÕES FINAIS}

A análise dos estatutos mostra falhas de governança, em potencial, nos clubes analisados. A análise foi feita nos estatutos sociais divulgados pelos clubes vigentes em outubro de 2016. Assim, o cenário apresentado pode ter sido alterado para 7 dos clubes que atualizaram seus estatutos recentemente.

Nos clubes da primeira divisão, a elite do futebol nacional, a governança está estruturada em seis conselhos, sendo eles a Assembleia Geral, o Conselho Deliberativo, o Conselho Fiscal, a Diretoria, o Conselho Administrativo e o Conselho Consultivo. Estes dois últimos são substitutos entre si, alternando-se na estrutura dos clubes. Assim, via de regra, há semelhança nas estruturas organizacionais dos clubes, como observado por Relvas et al. (2010). Os autores propõem que dentro de cada país há pouca variação nas estruturas.

Depreende-se dos resultados que a Assembleia Geral é o órgão máximo de deliberações do clube para assuntos específicos, contudo, como sua finalidade é limitada, o Conselho Deliberativo se torna o principal órgão de atuação interna do clube, com poder de deliberação sobre todos os assuntos relevantes. 
Não obstante, o Conselho Fiscal é o responsável pela fiscalização dos atos de gestão do clube, enquanto o Conselho Consultivo pelas discussões relacionadas aos aspectos históricos, tradicionais e sociais do clube, sendo que, devido a sua importância política na estrutura interna dos clubes, exerce influência decisiva na entidade. Estes resultados corroboram as afirmações de Carravetta (2006).

A comunicação identificada entre os órgãos que compõem a estrutura dos clubes embora legitimada pelo estatuto, pode não ser operante se no dia-a-dia do clube não for cumprida ou fiscalizada. A necessidade de prestar contas, comunicar e trocar informações entre os diferentes conselhos pode apresentar algum tipo de subordinação.

Como principais achados têm-se as omissões estatutárias capazes de instaurar diversos conflitos de interesses entre órgãos sociais e conselheiros/diretores, em que as questões políticas tendem a se sobressair em relação aos interesses comuns do clube. Identifica-se, então, que os problemas de governança pelos quais os clubes brasileiros passam podem ser decorrentes das lacunas, intencionais ou não, apresentadas pelos estatutos.

Os estatutos nada mais são que documentos elaborados, como via de regra, para respaldar as ações internas das organizações e não para orientar o comportamento dos envolvidos. Esse direcionamento deve ser dado pelos códigos de conduta. Diante disso, as lacunas encontradas nos documentos podem ser decorrentes da pressão exercida sobre os responsáveis pela elaboração dos estatutos e pelos diferentes interesses envolvidos.

Embora, todos os órgãos da estrutura organizacional dos clubes tenham a competência de discutir as alterações no Estatuto Social, órgãos políticos como o Conselho Deliberativo e Consultivo, exercem influência sobre os demais, de forma que suas exigências podem se sobrepor. Além disso, a aprovação do estatuto se dá em Assembleia Geral, composta, muitas vezes, por sócios que não conhecem as rotinas internas dos clubes nem mesmo a sua função e acabam votando em conformidade com os demais conselheiros. Portanto, é natural que lacunas sejam encontradas nos estatutos, pois eles são trabalhados ao longo do tempo dentro de interesses das partes envolvidas.

Diante destes resultados, vê-se que ainda são necessários estudos que analisem estas organizações e como estão estruturadas, para que cada vez mais o conhecimento sobre o futebol como negócio seja ampliado, e os clubes brasileiros entrem, enfim, para o seleto grupo de clubes que possuem uma gestão profissional, alcançando bons resultados dentro e fora de campo, contribuindo cada vez mais para o crescimento da economia local e a promoção de grandes espetáculos esportivos.

\section{REFERÊNCIAS}

Bács, É. B. M. (2014). Challenges to Professional Football Companies and their Answers with Particular Regard to Organisational Changes. Danube: Law and Economics Review, 5(2), 105-125.

Caravetta, E. S. P. (2006). Modernização da gestão no futebol brasileiro: perspectivas para a qualificação do rendimento competitivo (1. ed.) Porto Alegre: Editora Age.

Costa, C. E. S. \& Silva, R. C. (2006). Empresarização e controle organizacional: um estudo nos clubes de futebol de Santa Catarina. Cadernos EBAPE.BR, 4(4), 1-16.

Fatta, G. L., Barros, G. V., Pedroso, C. A. M. Q., Barros, M. A., Silva, T. C. A., \& Santos, A. A. R. (2016). Gestão e estrutura organizacional no futebol: uma revisão sistemática. Revista Intercontinental de Gestão Desportiva - RIGD, 6(2), 234-243.

Gurianova, E., \& Mechtcheriakova, S. (2015). Design of Organizational Structures of Management According to Strategy of Development of the Enterprises. Procedia Economics and Finance, 24, 395-401.

Leoncini, M. P., \& Silva, M. (2005). Entendendo o futebol como um negócio: um estudo exploratório. Gestão \& Produção, 12(1), 11-23.

Mattar, M. F. (2014). Na trave: o que falta para o futebol brasileiro ter uma gestão profissional (1. ed.) Rio de Janeiro: Elsevier.

Nagovitsin, A. (1983). The Management Structure of a Production Association. Problems in Economics, 26(1), $57-73$. 
Relvas, H., Littlewood, M., Nesti, M., \& Gilbourne, D. (2010). Organizational structures and working practices in elite European Professional Football Clubs: Understanding the relationship between youth and professional domains. European Sport Management Quarterly, 10(2), 165-187.

Rodrigues, M. S., \& Silva, R. C. (2009) A estrutura empresarial nos clubes de futebol. Organizações \& Sociedade, 16(48), 17-37. 